\title{
LA CONDICIÓN PÚBLICA DEL LENGUAJE Y LA AUTORIDAD DE LA PRIMERA PERSONA
}

MARK ROLLINS

INSTITUTO DE INVESTIGACIONES FILOSÓFICAS

Universidad Nacional Aứónoma de México

1. La literatura filosófica reciente ha sugerido que hay dos intuiciones relacionadas con el significado que pueden entrar en conflicto; a saber, que existe la autoridad de la primera persona sobre los significados de las oraciones de un hablante y que el lenguaje constituye en esencia un asunto público. Mi objetivo en este trabajo es, principalmente, mostrar cómo surge el aparente conflicto y rechazar alguna de sus soluciones más fáciles. Es decir, quiero mostrar que aquí hay un problema filosófico genuino y profundo. Al final del trabajo, haré un breve señalamiento sobre la dirección que ha de seguir una posible solución.

La intuición acerca de la autoridad de la primera persona queda en evidencia por la presunción que normalmente hacemos de que un hablante no puede estar equivocado acerca del significado de sus propias oraciones, una presunción que no se extiende a los significados que atribuimos a las oraciones de otros hablantes. Esto no implica que no se pueda corregir en lo absoluto a un hablante en lo relativo al significado de las oraciones que usa. En ocasiones, las personas emplean frases cuyos significados no son completamente claros, o nada claros, ni siquiera para sí mismas. La oración de un hablante puede carecer simplemente de significado. Más aún, es coherente con la intuición de la autoridad de la primera persona que un hablante pueda, en ocasiones, estar equivocado acerca de los significados convencionales de las palabras que utiliza; su aplicación de las palabras puede desviarse del uso típico de la mayoría de los hablantes con los que él se comunica. Más bien, la intuición se refiere a que, si la oración del hablante no tiene ningún significado, entonces éste consiste únicamente en lo que él intenta que la oración signifique, aun si sus significados no siempre están de acuerdo con los del diccionario. Es más, no debe tomarse la asimetría entre la primera y las otras personas como si implicara que el hablante, aunque posee autoridad sobre los significados de sus propias oraciones, no puede conocer los significados de las oraciones de los demás. El hecho de que uno pueda conocer los significados de las oraciones de los otros 
parece congruente (por lo menos a primera vista) con la tesis de la autoridad de la primera persona; es sólo que el carácter del conocimiento en el caso de la otra persona es de alguna manera diferente al de la primera. Se supone que aquello que el hablante sabe de forma automática sobre sus propias oraciones es algo que supuiestamente ha descubierto acerca de las oraciones de otros. ${ }^{1}$

Podemos detectar cierto grado de apoyo para la intuición sobre la autoridad de la primera persona en los escritos del último Wittgenstein. En relación con algunos puntos, Wittgenstein afirma que existe una asimetría entre el caso de la primera persona y los casos de terceras personas. Consideremos, por ejemplo la siguiente observación acerca del criterio para las imágenes de los colores,

¿Cuál es el criterio para la rojez de una imagen? Para mí, cuando la tiene el otro: lo que dice y hace. Para mí, cuando yo la tengo: nada. ${ }^{2}$

No he podido encontrar un pasaje donde Wittgenstein afirme explicitamente que existe la autoridad de la primera persona en relación con el significado, pero creo que podemos inferir tal tesis de las observaciones que hace acerca de este último, junto con pasajes como el que acabamos de citar. Sin embargo, de éste (y de muchos otros) se desprende una advertencia: Wittgenstein habría sido muy cauteloso con respecto a la afirmación de que el hablante conoce sus propios significados, porque esto puede llevarnos a pensar erróneamente que los significados son objetos mentales, accesibles por vía privada, o que podemos tener algún tipo de criterio privado o alguna fuente de justificación para nuestros significados; y éstos son puntos de vista sobre el significado que Wittgenstein rechaza explícitamente (regresaré más tarde a este punto).

La otra intuición, que el lenguaje es esencialmente un asunto público, es desde luego la que Wittgenstein comparte con los pragmatistas anteriores a él y, según creo, con la mayoría de los filósofos del lenguaje posteriores. Por lo general, se acepta que una de las doctrinas más sobresalientes e influyentes del último Wittgenstein es que no podemos siquiera entender la noción de lenguaje privado; aunque el acuerdo es mucho menos generalizado en lo tocante a qué significa realmente esa doctrina y sobre cuál es el argumento que la respalda. Espero que me perdonen entonces si aventuro sencillamente

1 Véase, Donald Davison, “First Person Authority”, Dialectica, vol. 38, 2-3 (1984), pp. 101-111. Si bien este trabajo se refiere principalmente a la autoridad de la primera persona sobre las actitudes proposicionales, el tema del significado aparece en las dos últimas páginas y me he basado en gran medida en esta exposición.

2 Ludwig Wittgenstein, Philosophical Investigations, $§ 377$; versión española: Investigaciones filosóficas, trad. de A. García Díaz y C. Ulises Moulines, Instituto de Investigaciones Filosóficas, UNAM - Editorial Crítica, México-Barcelona, 1988, p. 283. 
(y sin mucha defensa) una interpretación particular de Wittgenstein sobre este punto. Se trata de una interpretación ampliamente aceptada, y mi preocupación principal aquí es explorar algunas de sus consecuencias (tal como han sido desarrolladas por otros autores después de Wittgenstein). Tomaré el $\S 243$ de las Investigaciones filosoficas como clave para comprender lo que Wittgenstein quiere decir con privacía, según se aplica al lenguaje.

... Se podría también imaginar... hombres que hablasen sólo en monólogo. Acompañarían sus actividades hablando consigo mismos. - Un explorador que los observase y escuchase sus discursos podría conseguir traducir su lenguaje al nuestro...

¿Pero sería también imaginable un lenguaje en el que uno pudiera anotar o expresar sus vivencias internas - sus sentimientos, estados de ánimo, etc.- para su uso propio? - iEs que no podemos hacerlo en nuestro lenguaje ordinario?Pero no es lo que quiero decir. Las palabras de este lenguaje deben referirse a lo que sólo puede ser conocido por el hablante, a sus sensaciones inmediatas, privadas. Otro no puede, por tanto, entender este lenguaje. ${ }^{3}$

Más adelante (véanse los $\$ \S 264$ y 275) Wittgenstein se refiere explícitamente a ese lenguaje como un "lenguaje privado", y es la existencia de éste lo que él trata de negar, es decir, quiere negar que algo sea un lenguaje si no puede, en principio, ser entendido por otros. En consecuencia, quizás deberíamos decir que un lenguaje priblico (a saber, un lenguaje genuino, si Wittgenstein está en lo correcto) es aquel que, en principio, es comprensible por otros. Según entiendo a Wittgenstein, no serviría de contraejemplo a su rechazo de la idea de un lenguaje privado apuntar, por ejemplo, al último hablante del céltico de la isla de Man, pues el céltico de Man aún puede ser aprendido por otros. Se podría entonces reformular provechosamente la tesis de que el lenguaje es esencialmente público afirmando que el aprendizaje público constituye un criterio para reconocer al lenguaje. Siguiendo a Davidson y quizás a Quine (dos autores que discutiré más adelante), me gustaría dar un paso más allá y sugerir que la posibilidad de traducir o interpretar es un criterio para reconocer al lenguaje. Movernos de la posibilidad de aprender a la de interpretar equivale, de alguna manera, a dar un paso controvertido, pero espero que me excusen una vez más si dejo la controversia de lado. 4 Es importante notar que el $§ 243$ nos proporciona al menos alguna evidencia

3 Ibid., p. 219.

4 Pasar de la posibilidad de aprender a la de interpretar puede ser considerado como verosímil si pensamos que las condiciones objetivas externas bajo las cuales se aprende un lenguaje podrían ser tomadas como la evidencia empírica precisa que un intérprete necesita para entenderlo. Pero este movimiento puede seguir siendo controvertido a causa de que la posibilidad de interpretar (al contrario de la de aprender) implica una relación entre dos (o más) lenguajes, y no resulta claro que las constricciones generales de un idioma basten para garantizar que se 
de que Wittgenstein pudo haber querido respaldar también ese movimiento hacia la traducibilidad o la interpretabilidad. Entiendo, pues, la afirmación de que el lenguaje es en esencia público como un indicio de que sólo puede considerarse que la conducta verbal de los hablantes exhibe un lenguaje si esa conducta verbal es interpretable o traducible.

La preocupación inicial sobre si estas intuiciones o tesis son coherentes resulta, creo, fácilmente desechable. Anteriormente sugerí que la autoridad de la primera persona consiste en la afirmación de que mis palabras significan lo que yo intento que signifiquen, aun cuando mis significados no correspondan a aquellos que se encuentran en el diccionario de la comunidad. Esto parece entrañar que mis significados, o al menos algunos de ellos, pueden de hecho ser privados. Pero ello no implica privacidad en el sentido que le da Wittgenstein, pues mis palabras aún pueden ser interpretadas por otros, y si no es por medio del diccionario, lo serán por referencia a la evidencia empírica públicamente observable y relacionada con el uso de mi oración en varias ocasiones (o a las oraciones que se vinculan de manera gramatical y lógica con ella).

En realidad, parecería que, lejos de hallarse en conflicto, las dos tesis se pueden sostener al mismo tiempo, suponiendo que se acepte a una de ellas. Pues por un lado, ¿qué nos permite afirmar que lo que consideramos como autoridad de la primera persona es de hecho el significado de una oración, una característica lingüística, como opuesto a cierta idiosincracia mental privada que acompaña los usos que damos a esa oración? Que el lenguaje es esencialmente un asunto público y, por ende, que su significado es en esencia accesible públicamente constituye, según creo, la guía más firme que tenemos en este asunto; resulta difícil entonces afirmar que el significado es aquello de lo cual tiene autoridad la primera persona, a menos que se trate de una característica de la oración que otros pueden aprender o intepretar. Por otro lado, es difícil darle sentido a la interpretación a menos que uno presuma que un hablante no está equivocado sobre el significado de su propia oración. Asumiendo que lo que nos interesa primariamente es el significado del bablante, y no necesariamente el significado convencional de la comunidad, lo único que tendríamos que buscar en la interpretación es entonces el uso que hace el hablante de la oración en diversas circunstancias públicamente observables, y no tiene mucho sentido preguntarnos si el hablante está usando correctamente su oración. ${ }^{5}$

sostenga la relación pertinente entre dos lenguajes cualesquiera. (Pero, para que quede sentado, creo que ese paso es legítimo.)

5 Davidson, op. cit., p. 111. 
Yo quisiera sostener que esta línea de pensamiento es esencialmente correcta. A pesar de ello surge un conflicto cuando se trata de examinar con más detalle esas tesis y sus consecuencias.

2. Empecemos brevemente con la autoridad de la primera persona. Otra manera natural de expresar esta afirmación es diciendo que el hablante conoce el significado de sus propias oraciones. Esta manera de expresarse es correcta, pero (tal como Wittgenstein lo advertiría) nos podría hacer caer con facilidad en el error de pensar que los significados son, en cierto sentido, objetos que residen en la mente del hablante, accesibles por vía privada. Ésta es una concepción del significado que Wittgenstein rechaza enérgicamente y que Quine menosprecia más tarde como "el mito, del museo". Una variante de esta idea consiste en sostener que el significado de la oración (ya sea que se la conciba o no como un objeto mental) es algo que sólo puede ser determinado con la ayuda de una evidencia accesible de manera privada (quizás añadiéndola a la evidencia pública). Pero concebir la autoridad de la primera persona de esta forma entra en conflicto con la afirmación de que el lenguaje es público, es decir, de que puede ser interpretado por otros. Pues entender así a la autoridad de la primera persona implicaría que la evidencia requerida para determinar los significados no es públicamente accesible; la oración de un hablante no podría ser interpretada por otros. En contra de esto, Quine (citando a Dewey y a Wittgenstein como precedentes) argumenta que no hay otra cosa en el significado salvo lo que puede determinarse por medio de una evidencia empírica públicamente observable. En la terminología más precisa de Quine, no hay nada más en el significado de una oración que su "significado stimulus; en términos generales, podemos decir que dos oraciones son las mismas en cuanto a su significado stimulus si son respuestas apropiadas para todos y los mismos casos de experiencia. ${ }^{6}$

Pero, como sugerí anteriormente, la tesis de la autoridad de la primera persona no implica que los significados sean accesibles por vía privada, o que haya alguna evidencia privada para el significado de una oración. Rechazar el mito del museo no significa que debamos rechazar la autoridad de la primera persona. La afirmación de que un hablante conoce sus propios significados no equivale a decir que el hablante posee una fuente privada y especial de justificación, sino simplemente que no hay lugar a dudas. Solamente debemos presuponer que el hablante no está equivocado. Para llevar el punto un poco más lejos, podemos decir que el conocimiento que el hablante tiene de sus significados consiste en saber cómo usa una oración en circunstancias públicamente observables, y son justamente tales usos, en esas circunstancias,

6 W. V. O. Quine, Word and Object, MIT Press (1960), en particular el capítulo 2. La cita de Dewey y Wittgenstein aparece en "Relatividad ontológica" (conferencia de Quine sobre Dewey), en Ontological Relativity and Other Essays, Columbia University Press, 1969, p. 27. 
lo que constituye la evidencia públicamente observable que el intérprete necesita para interpretar.

Desafortunadamente, describir la autoridad de la primera persona de este modo no evita el conflicto. Porque necesitamos considerar otro punto importante, de aceptación general, que se relaciona con el significado, a saber, que este último no está determinado por una evidencia empírica, ni siquiera por la totalidad de la evidencia pasada, presente y futura. Quine es el defensor más destacado de esta afirmación ( $\mathrm{y}$ de lo que toma como sus consecuencias, la indeterminación del significado y la traducibilidad), y recordaré aquí muy sucintamente su argumento. Se nos pide que imaginemos la situación de un lingüista dedicado a la tarea de traducir un lenguaje tan extraño que para trabajar sólo cuenta con la evidencia empírica relacionada con el uso y el arte de sus oraciones en ocasiones diversas. Entonces el hablante pronuncia la oración "Gavagai" cuando pasa un conejo y el lingüista supone que "Gavagai" significa "conejo". Pero, desde luego, el lingüista podría intentar otras traducciones; por ejemplo, "estadio de un conejo" o "parte inseparable del conejo". Y el problema reside en que no parece haber una distinción empírica entre las opciones: un breve gesto que señala a un conejo es también un gesto que señala al estadio del conejo y a una parte inseparable de él. Mediante otra táctica, el lingüista puede hacer uso de una expresión nativa que se traduciría como "el mismo" y, cuando el conejo pasa por segunda ocasión, preguntar: “'el mismogavagai?" Si el nativo asiente, ello parecería decidir la cuestión en contra del "estadio del conejo". Pero en realidad, el problema persiste, pues el lingüista necesita considerar si la expresión nativa que tradujo inicialmente como "el mismo" no podría traducirse mejor como "estadio del mismo animal"; de aquí que "estadio de un conejo" siga siendo una posibilidad viable para la traducción de "gavagai". La evidencia empírica accesible para traducir la expresión nativa relacional en cuestión no parece ser independiente de la evidencia empírica para "gavagai" y expresiones semejantes. La observación de Quine consiste en que el problema va más allá de sus fronteras y atañe a nuestra traducción del lenguaje como un todo. ${ }^{7}$ Suponiendo que poseemos un manual para traducir un lenguaje, el cual se adecua a la totalidad de la evidencia empírica, siempre podemos encontrar otro manual de traducción que se adecue igualmente bien a esta última y, no obstante, ambos manuales pueden dar lugar a traducciones incompatibles de las mismas oraciones nativas. En este sentido, la traducción se encuentra subdeterminada por la evidencia empírica. Ahora bien, uno podría sentirse tentado a sugerir que es preciso que una de estas traducciones (y sólo una, dada su incompatibilidad mutua) sea la correcta. Sin embargo, la evidencia empírica por sí sola no basta para determi-

${ }^{7}$. Cf. la afirmación de Wittgenstein en el $\S 199$ de las Investigaciones. . . : "Entender una oración significa entender un lenguaje”. 
nar cuál es la correcta. Pero Quine rechaza esta línea de razonamiento porque sostiene que no hay nada más en el significado de lo que puede ser determinado empíricamente. Parecería que una consecuencia de esta tesis, conjuntamente con la tesis de la subdeterminación, consiste en que la traducción debe ser indeterminada, es decir, que sencillamente no existe un hecho positivo acerca de una $u$ otra de las traducciones, correctas a nivel empírico, que sea exclusivamente correcta. Una consecuencia ulterior de la tesis de la indeterminación consiste en que la referencia resulta inescrutable; en otras palabras, no existe un hecho positivo acerca de si el término "gavagai" del hablante se refiere a un conejo o a un estadio del conejo. El argumento de la indeterminación concierne primordialmente a la traducción de un lenguaje extranjero, pero las consecuencias se aplican a un nivel más próximo a lo nuestro. $\mathrm{Si}$ Quine tiene razón, resulta evidente que la indeterminación se aplicaría a la traducción o a la comprensión de los hablantes de nuestra propia comunidad, pues con frecuencia la homofonía y el diccionario son auxiliares deficientes, y el tribunal de apelación último, incluso en el caso de un compatriota, es la evidencia empírica. Y puesto que no existe nada en mis significados salvo lo que puede determinarse mediante la evidencia empírica, incluso éstos deben ser indeterminados.

El hecho de que la tesis de la indeterminación parece hallarse en conflicto con nuestras intuiciones acerca de la autoridad de la primera persona ha sido fundamentado categóricamente en un artículo reciente de John Searle, quien concluye que hay que abandonar esta tesis. ${ }^{8}$ Searle argumenta que, en realidad, Quine realizó una reducción al absurdo de una de sus propias premisas. La argumentación es breve: si los supuestos de Quine fueran acertados, entonces tendrían que ser correctos

... para nosotros los hablantes de inglés así como para los hablantes de la lengua gavagai. Y sabemos por experiencia propia que significamos con "conejo" algo diferente a "estadio de un conejo" o "parte inseparable de un conejo". Si mi connacional de habla inglesa, después de leer a Quine, decide que no puede decir si con la palabra "conejo" significo conejo, parte inseparable de un conejo o estadio de un conejo, tanto peor para él. Cuando recientemente vi un conejo, como en realidad sucedió, y lo llamé conejo, quise decir conejo. ${ }^{9}$

En lo que a mí concierne, es un hecho indiscutible que los significados de mis palabras son (al menos en términos generales) determinados, de modo que la tesis de la indeterminación debe ser falsa. Por lo tanto, una de las premisas del argumento de la indeterminación también debe ser falsa. Searle (como otros

8 John R. Searle, "Indeterminacy, Empiricism, and the First Person", Joumal of Philosophy, vol. 84, no. 3 (marzo de 1987), pp. 123-146.

9 Ibid., p. 126. 
críticos de Quine antes que él, principalmente Chomsky) acepta la tesis de la subdeterminación; en consecuencia, lo que debe rechazarse, según la opinión de Searle, es la tesis de que el significado constituye por entero un asunto empírico. ${ }^{10}$ Parecería que debemos concluir que existe algo más en el significado de lo que se puede determinar por la evidencia empírica públicamente observable. Esto puede conducir a pensar que hay un elemento esencialmente privado en el lenguaje. ${ }^{l l}$

Ahora bien, una respuesta que se podría dar en nombre de Quine es sencillamente mantenerse firme y rechazar la autoridad de la primera persona. Esto parece ser lo que hace Davidson en su artículo "The Inscrutability of Reference":

Quizás alguien (no Quine) se sienta tentado a decir: "Pero al menos el hablante sabe a qué se refiere". Habría que oponerse firmemente a este pensamiento. Las características semánticas del lenguaje son características públicas. Aquello que, por la naturaleza del caso, nadie puede descifrar a partir de la totalidad de la evidencia pertinente no puede formar parte del significado. $Y$ puesto que todo hablante debe saber esto, al menos en un sentido vago, ni siquiera puede intentar usar sus palabras para una referencia exclusiva, pues sabe que no hay forma de que sus palabras transmitan esa referencia a otro. ${ }^{12}$

Para expresarlo crudamente, no sabemos en realidad (con precisión) de qué estamos hablando.

Hay dos problemas con esta postura: en primer lugar, no parece ajustarse bien a las opiniones más positivas acerca de la autoridad de la primera persona que Davidson expresa en otros sitios; y, en segundo término, dicha postura parece totalmente inverosímil ( $y$ de hecho es aquí donde Searle termina, en lo fundamental, su discusión en torno al mismo pasaje). Trataré de ofrecer una especie de defensa de Davidson (y más indirectamente de Quine) en lo que respecta a este punto. En primer término, se puede seguir sosteniendo que tenemos la autoridad de la primera persona sobre los significados de nuestras oraciones, donde significado se concibe como un asunto enteramente público

10 En lo relativo a Quine, Searle rechaza explícitamente su conductismo. Pero más adelante en su artículo (donde también discute a Davidson, que no es conductista), este autor aclara que la reducción se lievaría a cabo contra la afirmación más general, que el significado es enteramente un asunto cmpírico.

11 Algunas de las observaciones de Searle en el artículo en cuestión podría llevarnos a pensar que sostiene que la evidencia pública debe ser complementada con alguna clase de evidencia privada, que existe algo esencialmente privado en el lenguaje, aunque es también un asunto primordiabncnte público. Las referencias de este autor al "contexto" y la "red" en ese artículo son demasiado breves como para proporcionar información; habría que acudir a su libro, Intentionality, para una explicación más clara.

12 Donald Davidson, "The Inscrutability of Reference", en su obra, Inguiries into Truth and Interpretation, Oxford University Press, 1984, p. 235. 
y empírico; sólo ocurre que esta clase de conocimiento no basta para permitirnos distinguir entre la aplicación que el hablante dé a "conejo" y a "estadio de un conejo". Y para que la posición parezca un poco más verosímil, podríamos agregar que el hablante sabe algo, o que por lo menos tiene algo en mente, que le permite distinguir entre conejos y estadios de conejos, pero ese algo, por ser privado, no puede expresarse como parte del significado de su oración, o parte de la referencia de sus términos. (La idea en este punto parece ser la misma a la que llega Quine con sus frecuentes referencias al problema del espectro invertido.) Incidentalmente, no existen razones para que Davidson o Quine nieguen que la gente realiza (y no de modo arbitrario) las distinciones que en efecto hace; y en realidad todos podemos aseverar firmemente al unísono la oración: "Cuando utilizo la palabra "conejo", quiero decir conejo, no estadio de un conejo". Pero no hay garantías de que la distinción que el otro tiene en mente corresponda a la que yo tengo en mente: las distinciones que el otro realiza pueden ser traducidas indeterminadamente a las que yo hago. Lo que Davidson y Quine niegan, entonces, es que parte de las distinciones que hacemos, como entre "conejo" y 'estadio de un conejo', reflejan o están en parte basadas en un conocimiento lingüístico (más precisamente, semántico).

Pero al reflexionar sobre ello, creo que esta línea de argumentación no logra solucionar el problema. Concedamos, por el momento, que Quine y Davidson afirman que el significado es por entero un asunto de evidencia empírica y pública. Y llamemos a este algo especial agregado, que se asocia con el uso particular que un hablante da a una oración y que sólo él sabe, el "esquisignificado" de la oración de ese hablante. Debemos notar que el uso que éste da a, por ejemplo, "conejo" y 'estadio del conejo' constituye una característica sistemática del comportamiento lingüístico del hablante; puede insistir en utilizar "conejo" de modo general (cuando un conejo está presente) y reservar 'estadio de un conejo' para casos fuera de lo común, como durante una conversación entre filósofos. Parece que, con el fin de explicar esta característica sistemática del comportamiento lingǘstico del hablante, debemos referirnos a su conocimiento del esquisignificado de sus oraciones. De este modo, parece difícil negar que este último es una característica linguiistica importante de las oraciones del hablante. Ya sea que se lo denomine significado, esquisignificado, o lo que se desee, la línea de razonamiento que hemos sugerido implica que una característica lingüística importante de la oración del hablante sólo puede ser conocida de manera privada, y esto entra en conflicto con la intuición concerniente al lenguaje que Quine y Davidson quieren conservar.

Por lo tanto, creo que no hay mucho que decir en defensa de la posición de Davidson. Como no podemos sencillamente abandonar nuestras intuiciones ordinarias relativas a la autoridad de la primera persona, debemos rechazar la indeterminación y, en consecuencia, también debemos rechazar la afirmación de que no existe otro elemento en el signficado excepto lo que puede determi- 
narse por medio de la evidencia empírica públicamente observable. ¿Implica esto que debemos abandonar la idea de que el lenguaje de un hablante tiene que poderse aprender $\mathrm{c}$ interpretar públicamente?

Pienso que no necesitamos aceptar esa conclusión. Más bien, podemos sostener que, aunque existe algo más en el significado de una oración de lo que podemos descubrir con la evidencia empírica y pública, ese elemento adicional también es público. En otras palabras, el elemento adicional no va a encontrarse en la evidencia, pero, no obstante, es compartido (o compartible) universalmente entre los hablantes, un elemento común a todos los seres capaces de aprender y utilizar el lenguaje. Esto puede constituir un primer paso importante en dirección de un punto de vista más racionalista de las capacidades mentales humanas (o, si no de un racionalismo en términos estrictos, entonces quizás de una perspectiva idealista trascendental, o de alguna clase de hipótesis sobre lo "innato", etc.). ${ }^{13}$ Pero no intentaré, en este artículo, seguir este razonamiento hasta allí. Más bien, la cuestión que me interesa en este lugar es más modesta e inmediata. Si uno se siente inclinado a pensar que la referencia a la evidencia empírica es esencial para la traducción y también que Quine expresó gran parte de la verdad con respecto a cómo se relaciona la evidencia empírica con la traducción, entonces la interrogante es: ¿Qué se necesita exactamente en una revisión de la doctrina de Quine con el fin de fundamentar adecuadamente nuestras intuiciones sobre la primera persona?

3. La línea particular de razonamiento que quiero seguir ha sido sugerida por el mismo Quine. ${ }^{14}$ Éste señala que en su práctica real, un lingüista suele escoger lo que parece ser la traducción "obvia" de manual en lugar de la "aviesa"; es decir, un linguiista práctico preferirá la traducción "conejo" antes que 'estadio de un conejo' (dado que son equivalentes a nivel empírico). Lo que aquí parece estar operando es una actitud de cariäad. En otras palabras, el lingüista práctico procede bajo el supuesto de que los demás son muy parecidos a nosotros con respecto a los significados y las creencias; o por lo menos, supone lo anterior hasta encontrar una buena comprobación empírica que lo contradiga. Sin embargo, manteniéndose fiel a la tesis de la indeterminación, Quine nos advierte contra la elevación de esta actitud práctica a la condición de un principio general de traducción. Sería un error, afirma, sostener que la traducción más obvia, caritativa, es más correcta que la aviesa, dado que ambas son equivalentes empíricamente.

Según creo, éste es el punto más prominente en que Davidson y Quine se separan. El primero eleva la actitud caritativa a un principio general de tra-

13 Véase, por ejemplo, Chomsky.

14 "Onthological Relativity", p. 34. 
ducción o interpretación. ${ }^{15} \mathrm{Y}$ generalmente parece que una de las motivaciones de Davidson para dar a la caridad un papel medular en la interpretación es precisamente reducir la indeterminación a un nivel tolerable. (Aún podemos admitir la indeterminación entre paráfrasis, entre formas distintas de decir lo mismo, pero no entre traducciones mutuamente incompatibles. $)^{16}$

El procedimiento de interpretación de Davidson es, en sus aspectos más esenciales, muy parecido al de Quine. No obstante, existe una diferencia particularmente importante: al enfrentarse con la evidencia de que un hablante sostiene que determinada oración es verdadera en ciertas circunstancias externas, Davidson recomienda que tomemos el objeto de la convicción como causa externa real de esa convicción, por lo menos en las primeras etapas de la interpretación. De esta manera, si un conejo se halla presente, interpretamos que el hablante está expresando la convicción de que el conejo se halla presente. Este procedimiento posee varias consecuencias obvias: en primer término, deja poco espacio para asignar un error al hablante (y por lo tanto, constituye un procedimiento claramente caritativo) y en segundo término, deja poco lugar para la indeterminación.

Sin embargo, tenemos razones para atribuir un error al hablante, en las últimas etapas de la interpretación, cuando intentamos elaborar una explicación coherente de la gramática del hablante y una interpretación sólida de sus palabras. Pero la caridad también sirve como principio guía en las últimas etapas; debemos tratar de llevar al máximo (u optimizar) el grado de verdad que (según nuestro entendimiento) asignamos al hablante. Fracasar en esto, afirma Davidson, equivale a correr el riesgo de convertir al hablante en un ser irracional (y por lo tanto, incapaz de usar un lenguaje). Inevitablemente, encontraremos que el hablante se equivoca en algunos puntos, "como el precio necesario de descubrir que está en lo correcto en otros". 17 Pero no

15 Esto se observa en una larga secuencia de trabajos acerca del significado y la interpretación radical, que comienza (según creo) con “Truth and Meaning” (1967), y se extiende hasta su obra más reciente.

16 La forma en que Davidson describe a la caridad y su significación varía sutilmente de trabajo en trabajo, y no siempre resulta claro si sigue una línea de razonamiento coherente. El punto de vista que le atribuyo posee su fundamento más sólido en "Radical Interpretation", "Belief and the Basis of Meaning" (véanse especialmente los últimos parágrafos) y el más reciente "A Coherence Theory of Truth and Knowledge", y su. fundamento más débil en los artículos sobre la inescrutabilidad de la referencia (como el que cité anteriorm ente). La caridad desempeña un papel muy menor en estos últimos trabajos. A primera vista, por lo menos, la posición de Davidson con respecto a la referencia puede parecer incoherente con sus posturas más generales en torno a la interpretación y, en particular, con los trabajos en que intenta sacar conclusiones epistemológicas y metafísicas sustanciales. Pero, como indicaré posteriormente en el contexto del tratamiento que hace Davidson del escepticismo, la apariencia de incoherencia puede ser engañosa.

17 "A Coherence Theory of Truth and Knowledge", en Henrich Dieter (ed.), Kant oder Hegel?, Klett-Cotta, Sttutgart, 1983, pp. 423-438. 
podemos interpretar que cae en un error masivo; en consecuencia, para que la interpretación tenga algún éxito (es decir, para que el hablante hable un lenguaje), debemos encontrar que la mayoría de sus convicciones coinciden con las nuestras.

Esta concepción de la interpretación sugiere que el elemento adicional que entra en la determinación de los significados de un hablante, a saber, el elemento adicional que puede ser encontrado en la evidencia empírica públicamente observable, es el contexto de la convicción del hablante, un contexto que, según lo afirma Davidson, debemos presuponer que es común (en su mayor parte) a todos los hablantes del lenguaje. Resulta claro que la invocación de la caridad reduciría la indeterminación a un nivel aceptable y, por lo tanto, suprimiría la fuente principal de conflictos con las intuiciones sobre la autoridad de la primera persona. De esta manera, parece tentador concluir en este punto que hemos encontrado la respuesta a nuestro problema original: dado el supuesto de que las convicciones contextuales son compartidas públicamente de un modo generalizado, podemos sostener que la intuición concerniente a la condición pública del lenguaje es en realidad coherente con la intuición de la autoridad de la primera persona.

Pero desafortunadamente, si pensamos un poco más las consecuencias de la teoría de Davidson, creo que podemos ver que el conflicto no está aún resuelto. Una de las consecuencias adicionales, en principio interesante, de la teoría de Davidson es una respuesta al escepticismo relativo a nuestras convicciones acerca del mundo exterior. La argumentación, según la he reseñado hasta el momento, demuestra (de tener éxito) que los hablantes de un lenguaje, cualquier lenguaje, deben estar de acuerdo en términos generales en sus convicciones acerca del mundo, y esto deja abierta la posibilidad de que el punto en que los hablantes están de acuerdo sea, no obstante, falso. Pero imaginemos por el momento un intérprete "omnisciente", un intérprete cuyas convicciones son efectivamente verdaderas en su totalidad, que se dedica a interpretarnos. Suponiendo que adopta el procedimiento de Davidson, encontraría que la mayoría de nuestras convicciones coinciden con las suyas, y esto implica hipotéticamente que son verdaderas. ${ }^{18}$

Los críticos han sugerido que este argumento no puede ser correcto de ninguna manera, si-consideramos los argumentos convencionales del escepticismo, como el del cerebro en la tina. En este caso, se nos pide que imaginemos una computadora que alimenta al cerebro con señales que simulan una escena momentánea del mundo ordinario, y en consecuencia el cerebro emite un monólogo que para todo el mundo parece referirse a conejos, mesas, si-

18 El argumento del intérprete omnisciente aparece por primera vez en "The Method of Truth in Metaphysics". 
llas, etc. En tal caso, debemos concluir aparentemente que la mayoría de las convicciones del cerebro son falsas.

La respuesta de Davidson a este argumento debe ser considerada como una consecuencia natural de su teoría de la interpretación. El problema con el razonamiento precedente es que hemos malinterpretado al cerebro, nos hemos guiado equivocadamente por la homofonía. El procedimiento que debemos seguir con el cerebro es igual al que seguimos con cualquier otro hablante: hay que tomar los objetos de sus convicciones como causas externas reales. En este caso, las causas son los hechos electrónicos de la computadora. De aquí que, cuando el cerebro utiliza de manera engañosa las palabras “conejo", 'mesa' y 'silla', debemos interpretar sus oraciones como referidas a hechos electrónicos, en cuyo caso la mayoría de sus convicciones resultarán verdaderas.

En el momento en que se examina el caso del cerebro en la tina desde el punto de vista de la primera persona, reaparece el conflicto entre lo público y la autoridad de la primera persona. Doy por supuesto que si se cuestiona a un individuo sobre este tema, insistirá en que su cerebro se encuentra en su cuerpo humano y que tiene una conciencia directa de los conejos, las mesas y las sillas. Pero supongamos que, de hecho, ese individuo es verdaderamente un cerebro en una tina conectada a una computadora (sin que él lo sepa, un científico ha extraído su cerebro, etc.). Supongamos también que un intérprete omnisciente procede a interpretar sus emisiones de acuerdo con el método de Davidson. De este modo, el intérprete omnisciente descubrirá que la oración "hay un conejo en el campo" significa realmente: "El evento electrónico tal y cual se está produciendo en el transistor tal y cual". Desde luego, el intérprete le asignaría como verdaderas la mayoría de sus convicciones y quizás esto sea una causa de alivio, pero existe también un aspecto perturbador. Pues parece que, aunque en su oportunidad el individuo puede creer que habla de conejos que saltan entre los matorrales, está hablando en realidad, según la línea de razonamiento de Davidson, de electrones que saltan entre transistores. Nuestra creencia intuitiva de que hablamos de conejos es un error. Por lo tanto, parece que al descartar el escepticismo global acerca de la posibilidad de que alguna vez sepamos si una de nuestras convicciones es verdadera, lo hemos sustituido por un escepticismo nuevo acerca de la posibilidad de que alguna vez sepamos de qué estamos realmente hablando. $Y$ ello entra en conflicto obviamente con nuestras intuiciones sobre la autoridad de la primera persona.

Creo que Davidson podría ofrecer una especie de réplica a esta objeción. Si queremos contemplar la creencia intuitiva de que hablamos de conejos como convicción genuina, ésta se tiene que poder expresar como una oración que el intérprete omnisciente sea capaz de interpretar, por lo menos así lo parecería si aceptamos la tesis concerniente a la condición pública del lenguaje. Por lo 
tanto, supongamos que expresamos la convicción de esta forma: "Cuando utilizo la palabra 'conejo', estoy hablando de un conejo". El problema es que, dado el uso de la palabra "conejo" en esa oración (es decir, la palabra en itálicas, no entre comillas), el intérprete entenderá que hablamos de las mismas cosas a las que siempre nos referimos cuando empleamos la palabra "conejo", a saber, electrones y transistores de la computadora. De modo que la creencia intuitiva acerca del objeto de que estamos hablando resulta ser a la vez verdadera y coherente con la interpretación del intérprete omnisciente y no parece plantearse la duda escéptica.

Pero obviamente, a esta línea de razonamiento se le escapa el sentido real de nuestra intuición de la primera persona según la cual estamos hablando de conejos, no de hechos electrónicos, sino de mamíferos brincadores de largas orejas. De forma que quizás debemos considerar a la intuición de la primera persona, según la cual hablamos de conejos, como una simple creencia que no puede expresarse en una oración sujeta a interpretación. Pero ello parece conducirnos directamente a la posibilidad de un lenguaje privado. Aparentemente, pues, el conflicto entre nuestra intuición concerniente a la autoridad de la primera persona y la relativa a la condición pública del lenguaje sigue existiendo.

Como lo sugiere su postura con respecto a la referencia, Davidson puede estar dispuesto a vivir con un rechazo (parcial) de la intuición sobre la autoridad de la primera persona al sostener que, en ocasiones, lo que creemos que significamos puede no ser lo que realmente estamos significando, y lo que realmente estamos significando es lo que el intérprete ideal entendería que significamos. Quizás Davidson no es el único que asume esta posición.

Hilary Putnam ha dado una argumentación contra el escepticismo que, a pesar de algunas diferencias obvias, tiene varios puntos importantes en común con la de Davidson. Más precisamente, Putnam afirma que no podemos entender la noción de que una teoría que en términos epistémicos es ideal, resulte, no obstante, falsa. Pues (según argumenta Putnam) una teoría ideal debe ser por lo menos congruente; en consecuencia, de acuerdo con el teorema de Loewenheim-Skolem, debe existir un modelo de esa teoría (es decir, una interpretación tal que la teoría resulte verdadera). Contra la objeción tan obvia de que el modelo quizás no sea la interpretación pretendida de la teoría, Putnam replica que no podemos basar una teoría de la interpretación en elementos tan marginales como las intenciones.

Putnam puede tener razón con respecto a las intenciones, pero el verdadero fin de la objeción es que el modelo tal vez no se adecue a lo que, desde el punto de vista de la primera persona, podamos creer que significamos con la teoría. Se podría sostener que, cualquiera sea el resultado de nuestra explicación sobre la interpretación (ya sea que se refiera a las intenciones o a otras cosas), una de las constricciones para una explicación correcta es que las 
interpretaciones de teorías específicas deben ser congruentes con nuestras intuiciones acerca de la primera persona. Putnam debe hallarse preparado para rechazar esa línea de razonamiento, es decir, para rechazar (al menos parcialmente) la tesis concerniente a la autoridad de la primera persona para que su argumentación contra el escepticismo pueda funcionar. Pero, igual que en el caso de Davidson, esto parece sustituir sencillamente la duda escéptica sobre la verdad de nuestras convicciones más firmes con una duda escéptica acerca de la posibilidad de que sepamos los significados reales de nuestras oraciones.

4. Los argumentos de Davidson y Putnam no pueden ser considerados respuestas genuinas al escepticismo, y como pienso que nuestra intuición sobre la autoridad de la primera persona es sólida, mi propia inclinación es rechazar cualquier explicación de la interpretación que no satisfaga esa intuición. En términos davidsonianos, yo afirmaría que la explicación correcta de la interpretación sería aquella en la cual el intérprete omnisciente asume que estamos significando exactamente lo que, desde el punto de vista de la primera persona, nosotros suponemos que significamos. $\mathrm{Y}$ de un modo más general (por las razones planteadas al final de la primera sección de este trabajo), quisiera afirmar que la satisfacción de ambas intuiciones - la concerniente a la autoridad de la primera persona y la que se refiere a la interpretabilidad pública del lenguaje - debe ser contemplada como una constricción para cualquier teoría adecuada del significado.

No conozco ninguna teoría presente del significado que satisfaga claramente a esa constricción. Desde luego, hay aproximaciones al significado que no parecen afrontar de manera inmediata el conflicto en cuestión, pero en su mayoría son aproximaciones que evitan el conflicto sólo porque ignoran o dejan de lado una explicación clara y detallada de cómo es posible la interpretación. Cualesquiera sean las otras nociones (bajo la forma de "intenciones", "contexto", "estructura profunda", etc.) que una teoría acabada incluya en la comprensión del significado, también debe contener o implicar una explicación clara y detallada de la interpretación para que pueda considerarse que satisface nuestras intuiciones acerca de la condición pública. De esta manera, el problema consiste en hallar una explicación adecuada de la interpretación que satisfaga también nuestras intuiciones sobre la autoridad de la primera persona. Como hemos visto, las dos mejores explicaciones existentes en la actualidad, la de Quine y la de Davidson, fracasan justamente en este punto.

Quisiera esbozar de manera sucinta algunos de los elementos que, según creo, podrian formar parte de una teoría enteramente adecuada de la interpretación. Creo que Davidson nos ha llevado muy cerca de esa teoría, pero el conflicto con la autoridad de la primera persona parece surgir como consecuencia del principio caritativo de que tomamos (en términos generales) al objeto de una convicción como su causa externa. Se podría sugerir, como 
alternativa al principio de Davidson, que asumimos que el objeto de la convicción es cualquier elemento que considerariamos como la causa tipica del patrón de estímulos que origina a la convicción, es decir, tomamos al patrón de estímulos (o alguna causa inmediata semejante) como la clave para la interpretación. Por cuanto, en raras ocasiones como en el caso del cerebro en la tina, los patrones de estímulos pueden tener causas atípicas, el enfoque que estoy sugiriendo nos permitiría interpretar al cerebro de una forma que concuerde con nuestras intuiciones de la primera persona. Desafortunadamente, esta perspectiva destruiría además la argumentación davidsoniana contra el escepticismo. Más preocupante aún es que esta concepción de la interpretación, al volver a invocar los patrones de estímulos, representaría obviamente una amenaza para el punto de vista de Quine, y cabe la interrogante de si el enfoque propuesto no resucitaría al espectro de la indeterminación de este último filósofo y a sus conflictos con la autoridad de la primera persona. Creo que puede elaborarse una teoría que siga las líneas de razonamiento sugeridas y que eluda el conflicto con la autoridad de la primera persona, pero quizás éste no es el lugar para desarrallarla. ${ }^{19 *}$

19 Esta teoría de la interpretación se encuentra elaborada hasta cierto grado, y justificada con razones totalmente independientes de las consideraciones sobre la autoridad de la primera persona, en el tercer capítulo de mi disertación todavía inédita.

- El autor agradece a Ana Isabel Stellino su valiosa ayuda en la redacción en español de este trabajo. 